\title{
A PERCEPÇÃO DOS AFFORDANCES EM MAÇANETAS DE AUTOMÓVEIS
}

\section{THE PERCEPTION OF AFFORDANCES IN DOOR HANDLES OF AUTOMOBILES}

\author{
Manuela Quaresma ${ }^{1}$, D.Sc. \\ Bruno Medina ${ }^{1}$, graduando em Design \\ Mariah Loureiro ${ }^{1}$, graduanda em Design \\ Danila Gomes ${ }^{1}$, M.Sc.
}

(1) LEUI | Laboratório de Ergodesign e Usabilidade de Interfaces - PUC-Rio

e-mail:mquaresma@puc-rio.br

e-mail:brunoselim@hotmail.com

e-mail:mloureiroc@gmail.com

e-mail: danilagomespe@gmail.com

Ergodesign, Design de Produto, Affordance, Eyetracking, Automóveis.

Este artigo é resultante de uma pesquisa que verificou como as maçanetas dos automóveis são percebidas pelos usuários. Com o auxílio do Eyetracking pôde-se perceber quais os pontos mais facilmente notados nas maçanetas pelos participantes dos testes e quais as características atribuídas a cada uma delas, levando em consideração a sua forma.

Ergodesign, Product Design, Affordance, Eyetracking, Automobiles.

This article is the result of a research that verified how the door handles of the automobiles are perceived by the users. Using Eyetracking, it was possible to see which points were easily noticed on the door handles by the participants of the tests and what characteristics were assigned to each one, taking into account their shape.

\section{Introdução}

Atualmente, a indústria de automóveis representa uma grande variedade de modelos de veículos e, com isso, também diversos modelos de dispositivos e artefatos em seu interior, como nos painéis frontais e laterais ou nas maçanetas externas e internas das portas. Dessa maneira, os affordances encontrados antigamente nessas peças podem não ser mais presentes atualmente, o que pode levar o usuário a não compreender completamente como interagir com tal produto.

Affordance, termo ainda sem tradução para o português criado por James Gibson (Gibson, 1979), se refere à informação que todos os objetos 


\section{$16^{\circ}$ \\ ERGODESIGN USIHC CINAHPA}

passam para o usuário com relação ao modo como este deve manuseá-lo, assim como as ações possíveis de serem realizadas com tal produto. Segundo Gibson (1979), essas informações devem ser entendidas por todos os usuários,

independentemente de suas experiências, contexto em que está inserido e conhecimentos adquiridos antes de se deparar com tal objeto. Placas auxiliares e legendas explicativas caracterizam um affordance mal empregado, uma vez que os usuários deveriam entender como interagir com os objetos sem ajudas externas a ele.

Outro pesquisador, Donald Norman (1999), usou, posteriormente, o mesmo termo em seus estudos, mas empregado de maneira diferente. Para ele, os affordances de um produto eram compreendidos com base no contexto em que o produto e o usuário estão inseridos, assim como nos conhecimentos e experiências prévias dos mesmos. Por conta disso, fatores culturais também influenciavam diretamente na percepção e compreensão que as pessoas têm dos diferentes produtos que surgiam no mercado.

Surgiram outras aplicações para o termo affordance, como é o caso de hidden affordance, termo usado para designar os affordances que não são percebidos imediatamente pelos usuários. Dessa maneira, algumas possibilidades do produto ficam ocultas e são descobertas somente em decorrência do uso dos mesmos.

Com base nesses conceitos, nessa pesquisa, pretendeu-se entender se e como os affordances presentes nos automóveis são percebidos e entendidos pelos usuários. Dentre os comandos que mais sofreram modificações com o passar do tempo, as maçanetas de portas externas dos carros foram as que provavelmente mais se modificaram devido à grande possibilidade de formatos $\mathrm{e}$ mecanismos que podem adquirir em diferentes modelos de automóveis. Por conta disso, para esta pesquisa, esses produtos foram selecionados como principal objeto de análise. Por meio do uso do aparelho Eyetracking, buscou-se entender quais os principais pontos percebidos em maçanetas de carros, procurando responder se de fato o usuário entende as informações que estes objetos passam.

\section{Problema}

O desenvolvimento de novos modelos de carros é cada vez mais habitual na indústria automobilística, fazendo com que a diversidade de opções também aumente. Dessa maneira, surgem produtos novos com grande frequência e o usuário nem sempre acompanha essas mudanças. Um exemplo disso são os pinos da trava das portas, uma vez que, há alguns anos, era comum observar pinos internos para travar as portas dos veículos, que indicavam ao usuário quando a porta estava travada ou não por meio da posição que apresentavam - para cima a porta ainda estava aberta e para baixo estava travada. Os mesmos não são mais vistos em carros mais modernos, tendo sido substituídos por modelos mais discretos e com manuseios diferentes, já que estes ocupam sempre a mesma posição, não fornecendo um feedback necessário ao usuário.

Atualmente, também, as maçanetas podem possuir novas características e atributos, como leitura de impressão digital, travas desbloqueadas por senhas ou botões que substituem as chaves. Tais opções podem confundir o usuário quanto ao manuseio dessas novas tecnologias, já que ele pode não estar habituado a determinados comandos e ações. Com a velocidade de mudanças nos produtos cotidianos cada vez maior, os affordances, ou seja, as informações que os produtos passam aos usuários que dizem como tal objeto deve ser manuseado, presentes nessas novas versões também mudam e podem não ser entendidas com clareza pelos usuários, o que pode causar constrangimento aos mesmos e demais pessoas.

\section{Metodologia}

Para a realização desta pesquisa foi usado o aparelho Eyetracking com o intuito de monitorar e gravar os movimentos oculares dos participantes durante a realização do teste de percepção de forma. Por meio da emissão de raios infravermelhos, este suporte, instalado a um computador e acompanhado de um software próprio, permite acompanhar quais os pontos o participante olha na imagem mostrada no monitor. Dessa maneira, foi possível manter o registro de 


\section{$16^{\circ}$ \\ ERGODESIGN USIHC CINAHPA}

$16^{\circ}$ Ergodesign - Congresso Internacional de Ergonomia e Usabilidade de Interfaces Humano Tecnológica: Produto, Informações Ambientes Construídos e Transporte

$16^{\circ}$ USIHC - Congresso Internacional de Ergonomia e Usabilidade de Interfaces Humano Computador

CINAHPA | 2017 - Congresso Internacional de Ambientes Hipermídia para Aprendizagem. quais os pontos mais vistos ou por quanto tempo os olhos se demoraram em determinada área da imagem.

No decorrer dos testes foi utilizado o método de diferencial semântico, a fim de entender quais as características seriam atribuídas a cada maçaneta. Utilizou-se também um questionário no final do teste, com a finalidade de compreender o nível de relação do participante com a utilização de automóveis. O participante era indagado sobre a sua rotina no uso de automóveis.

\subsection{Preparação do Teste}

Para tornar esta pesquisa possível, determinou-se que seria realizado um teste de percepção de forma usando imagens de maçanetas externas de portas de carros mostradas em uma tela de computador, com o auxílio do aparelho Eyetracking, a fim de monitorar os pontos visualizados pelos participantes. Foi definido que este teste seria realizado com 20 participantes diferentes, escolhidos aleatoriamente, e aos quais era pedido que identificassem algumas imagens selecionadas, assim como que as classificassem de acordo com uma série de características.

Começou-se, então, a procurar por exemplos de maçanetas encontradas em carros atualmente. Por conta da grande variedade de modelos foram selecionadas dez maçanetas a fim de analisar como estes objetos são percebidos pelos usuários, buscando por formas e mecanismos de manuseio presentes no cotidiano brasileiro ou não, além de opções de maçanetas bem diferentes entre si com o objetivo de ter uma visão mais ampla da percepção dos participantes sobre diferentes modelos do mesmo produto.

Para que isso fosse possível, realizou-se um teste no qual a proposta era questionar cada um dos 20 participantes sobre seu entendimento do objeto mostrado isoladamente, bem como o modo que deveria ser manuseado. Para evitar respostas tendenciosas e influenciadas por outros atributos, as imagens foram retiradas de seu contexto, procurando-se evitar ao máximo que portas e janelas de carros aparecessem, assim como demais partes no entorno das maçanetas que pudessem indicar qual o objeto em questão. Além disso, para não haver influência de diferentes cores, foi determinado que todas as maçanetas aparecessem na cor prata.

Por conta da grande variedade de exemplos deste produto, sabia-se que alguns mecanismos de manuseio presentes nas mesmas eram mais difíceis de identificar do que outros, devido principalmente à falta de familiaridade que os participantes apresentavam com os modelos em questão. Apesar de serem modelos encontrados atualmente no mercado, nem todos os exemplos estão presentes nos carros brasileiros. Optou-se, também, por selecionar modelos em que a própria maçaneta estivesse oculta e, em consequência, o affordance também não fosse facilmente percebido (hidden affordance), a fim de dificultar a percepção e identificação da maçaneta, além de prestigiar os mais diferentes modelos possíveis.
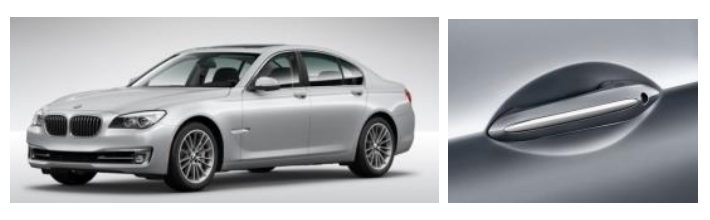

Figuras 1 e 2. Carro BMW 7 Series (1) e sua maçaneta (2)

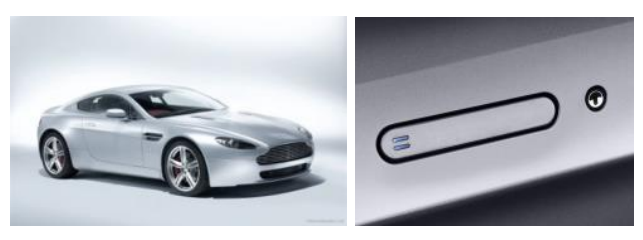

Figuras 3 e 4. Carro Aston Martin V8 (3) e sua maçaneta (4)

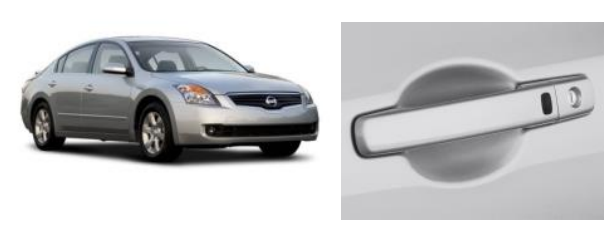

Figuras 5 e 6. Carro Nissan Altima (5) e sua maçaneta (6) 


\section{$16^{\circ}$ \\ ERGODESIGN \\ USIHC CINAHPA}
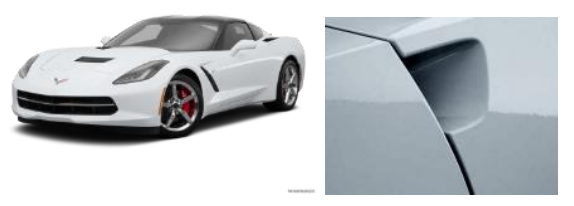

Figuras 7 e 8. Carro Chevrolet Corvette (7) e sua maçaneta (8)

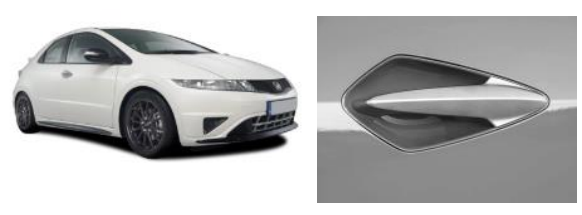

Figuras 9 e 10. Carro Honda Civic i-CTDi (9) e sua maçaneta (10)
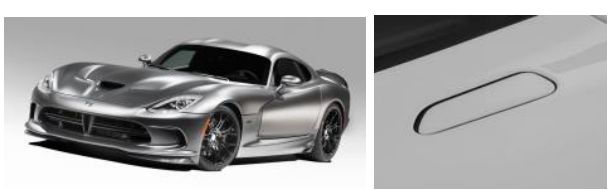

Figuras 11 e 12. Carro SRT Viper GTS Coupe (11) e sua maçaneta (12)
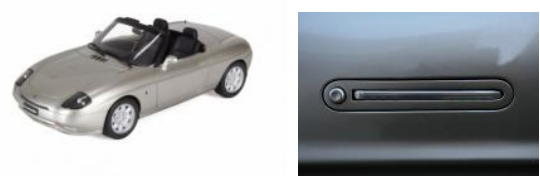

Figuras 13 e 14. Carro Fiat Barchetta (13) e sua maçaneta (14)

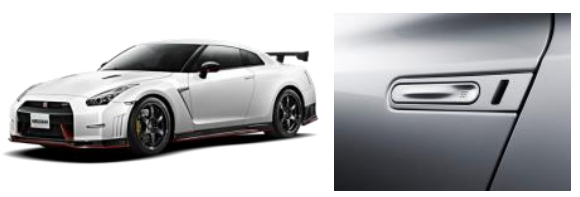

Figuras 15 e 16. Carro Nissan GT-R (15) e sua maçaneta (16) $16^{\circ}$ Ergodesign - Congresso Internacional de Ergonomia e Usabilidade de Interfaces Humano Tecnológica: Produto, Informações Ambientes Construídos e Transporte

$16^{\circ}$ USIHC - Congresso Internacional de Ergonomia e Usabilidade de Interfaces Humano Computador

CINAHPA | 2017 - Congresso Internacional de Ambientes Hipermídia para Aprendizagem.
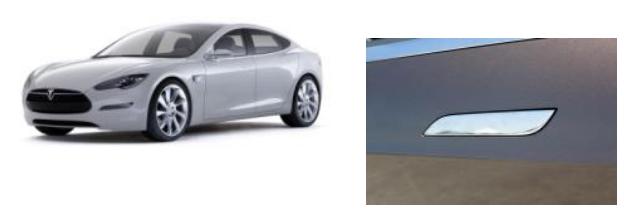

Figuras 17 e 18. Carro Tesla Model (17) e sua maçaneta (18)

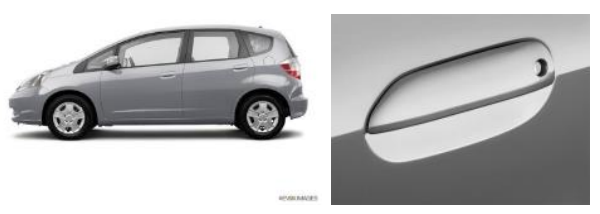

Figuras 19 e 20. Carro Honda Fit (19) e sua maçaneta (20)

Definiu-se também uma separação inicial para o uso das imagens nos testes. Dessa maneira, cada participante veria cinco imagens, dentre as dez selecionadas. Para evitar que algum participante fosse privilegiado por maçanetas mais "fáceis", ou seja, que tivesse que identificar exemplos mais comuns ao seu cotidiano e, por isso, mais facilmente reconhecíveis, optou-se por misturar modelos de maçanetas mais comuns no mercado brasileiro com outras mais distantes deste cenário, o que fazia com que todos os participantes se vissem confrontados com exemplos de diferentes maçanetas e mecanismos de manuseio.

Após a seleção das maçanetas que seriam usadas nos testes, começou-se a pensar em quais perguntas seriam feitas aos participantes durante sua realização, assim como na estrutura e desenvolvimento do mesmo. Decidiu-se que cada participante analisaria cinco imagens, dentre as dez selecionadas, e que depois de mostrar cada uma individualmente, seria pedido a ele que classificasse a maçaneta de acordo com uma escala de diferencial semântico, composta de sete pares de características opostas.

As características usadas na escala de diferencial semântico foram baseadas em outras usadas por Shang H. Hsu (Hsu, 1998), usadas para classificar telefones. Foi usada uma escala de sete pontos,
Realização:

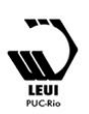




\section{$16^{\circ}$ \\ ERGODESIGN USIHC CINAHPA}

repetida a todos os sete pares de características (Figura 21). Após essa etapa, foram mostrados oito desenhos para exemplificar os principais modelos de carros presentes no mercado, juntamente com seus respectivos nomes, e foi pedido aos participantes que dissessem em quais achavam que poderiam encontrar determinada maçaneta, levando em consideração o formato da mesma com relação ao modelo do carro e as características atribuídas anteriormente, como mostrado na Figura 22. Depois disso, foi realizado um pequeno questionário com o participante, no qual foi perguntado sobre seu cotidiano de uso do carro.

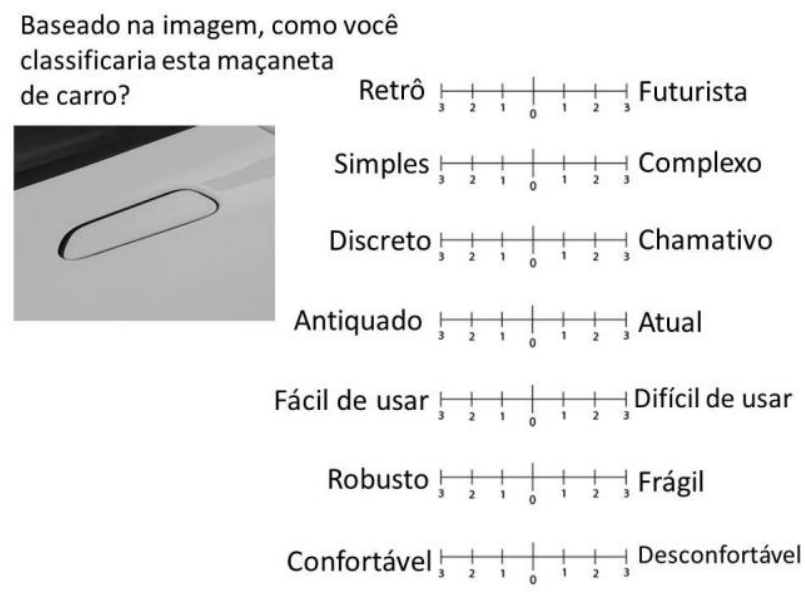

Figura 21. Escala de diferencial semântico final

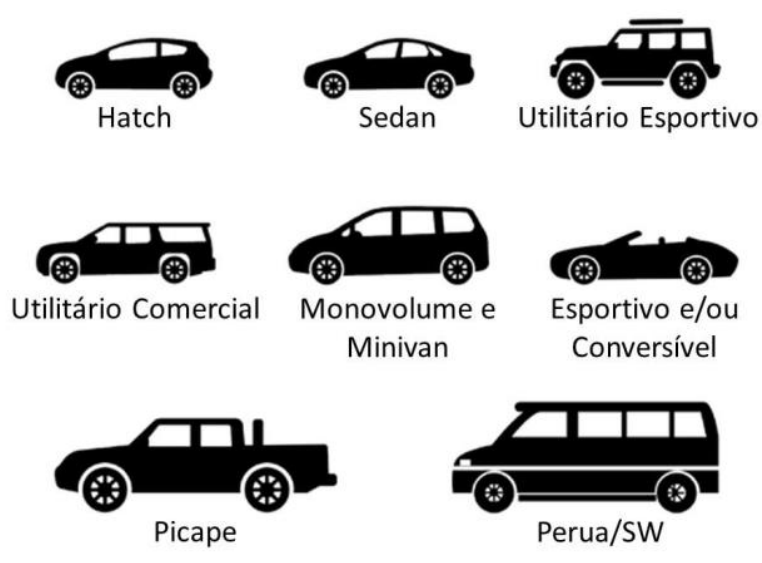

Figura 22. Versão final dos desenhos usados nos testes

\subsection{Teste piloto}

$16^{\circ}$ Ergodesign - Congresso Internacional de Ergonomia e Usabilidade de Interfaces Humano Tecnológica: Produto, Informações Ambientes Construídos e Transporte

$16^{\circ}$ USIHC - Congresso Internacional de Ergonomia e Usabilidade de Interfaces Humano Computador

CINAHPA | 2017 - Congresso Internacional de Ambientes Hipermídia para Aprendizagem.
Antes da realização dos testes definitivos foram realizados testes piloto com o intuito de testar a abordagem e perguntas dos testes. Por meio deles, algumas questões puderam ser resolvidas, como por exemplo, o diferencial semântico, etapa que causava dúvidas nos participantes. Primeiramente, não se usou números ou outro tipo de diferenciação para os pontos na escala, deixando apenas as demarcações na linha correspondente a cada par de características. Como o participante deveria ficar imóvel devido ao uso do aparelho Eyetracking, uma das pesquisadoras marcava para ele, em um computador auxiliar, o ponto desejado. Essa tarefa ficou mais difícil devido à falta de denominações mais específicas para os pontos. Sendo assim, após perceber esse problema nos testes piloto, os pontos foram numerados de maneira a deixar o meio neutro (0) e os demais pontos variando de um (1) a três (3) para ambos os lados. Optou-se por não usar números positivos e negativos antes ou depois do zero a fim de não influenciar na percepção do participante, que poderia considerar uma característica inferior a outra por aparecer relacionada a um número negativo, por exemplo.

Algumas características presentes na escala também geraram dúvidas, como por exemplo, os pares "velho" x "novo" e "antiquado" x "futurista", por conta, principalmente, da sua proximidade de significados. Por conta disso, optou-se por mudálos para "retrô" x "futurista" e "antiquado" x "atual". Os primeiros se referem a características da forma relacionadas a atributos mais extremos das maçanetas, como um desenho mais arrojado ou vanguardista, enquanto os últimos se relacionam a características mais comuns do cotidiano.

Em alguns testes piloto também se pôde perceber que alguns participantes tinham suas respostas influenciadas pela cor dos carros mostrados nas fotos, usadas em sua cor original. Por conta disso, optou-se por padronizá-las, mudando a cor dos carros para a prata, a fim de deixar esse atributo o mais neutro o possível e minimizar sua influência nas respostas dos testes. Algumas imagens foram substituídas por outras originalmente já nessa cor e, para aquelas em que não foi possível encontrar na opção desejada, foi necessário manipular digitalmente as escolhidas anteriormente. 


\section{$16^{\circ}$ \\ ERGODESIGN USIHC CINAHPA}

$16^{\circ}$ Ergodesign - Congresso Internacional de Ergonomia e Usabilidade de Interfaces Humano Tecnológica: Produto, Informações Ambientes Construídos e Transporte

$16^{\circ}$ USIHC - Congresso Internacional de Ergonomia e Usabilidade de Interfaces Humano Computador

CINAHPA | 2017 - Congresso Internacional de Ambientes Hipermídia para Aprendizagem.

\subsection{O teste}

Antes de dar início a cada teste era preciso calibrar o Eyetracking para que o rastreamento dos olhos fosse o mais preciso possível, o que influencia diretamente nos resultados obtidos e, consequentemente, nas análises dos dados posteriormente. Dessa maneira, após assinar o termo de consentimento livre e esclarecido (aprovado em Comissão de Ética), era pedido ao participante que se sentasse de maneira confortável e olhasse fixamente a tela do computador de forma a calibrar o aparelho. É importante ressaltar que também era pedido para que o participante não se mexesse muito durante a realização do teste, procurasse não obstruir a leitura do aparelho com movimentos das mãos e também que evitasse olhar para outras direções diferentes da tela, evitando assim que o aparelho perdesse o movimento ótico por tempo significativo. Para evitar dúvidas e receios, também era explicado verbalmente, além de constar no termo de consentimento escrito, que o Eyetracking não iria machucar o participante de nenhuma forma e que o teste não visava testar as capacidades intelectuais dos mesmos, apenas saber qual era o entendimento deles sobre o que era mostrado. Duas pesquisadoras participavam dos testes, uma vez que uma interagia com o participante, fazendo perguntas ao longo da realização dos testes e respondendo a possíveis dúvidas, enquanto a outra se encarregava de calibrar o Eyetracking para cada participante e marcar as opções escolhidas nas escalas de diferencial semântico, conforme apresentado nas imagens 23, 24, 25 e 26 abaixo.
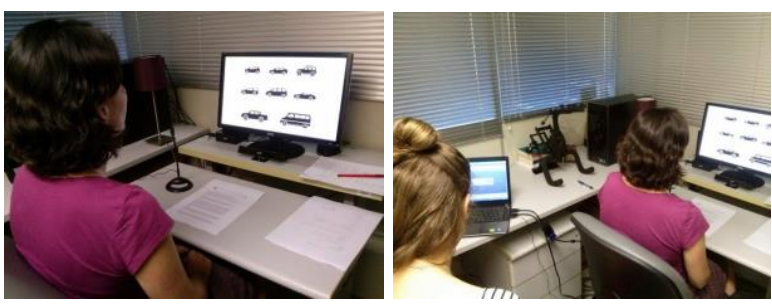

Figuras 23 e 24 . Fotos representativas da realização dos testes, mostrando a posição do participante durante os mesmos
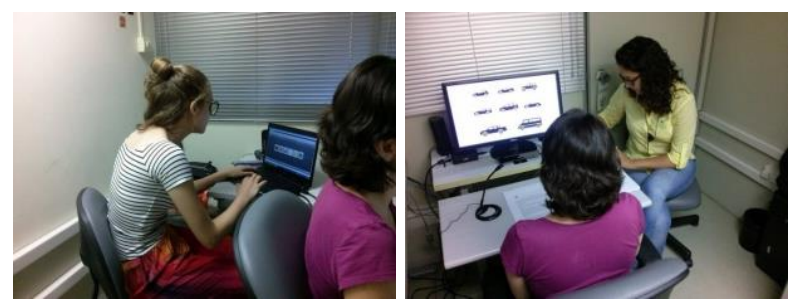

Figuras 25 e 26 . Fotos representativas da realização dos testes, mostrando a posição de ambas as pesquisadoras com relação ao participante

Após essa etapa era, então, começado o teste de fato. Foi pedido a cada participante que identificasse cinco imagens individualmente, uma de cada vez, e, em casos de acerto, que explicasse como faria para abrir a porta do carro usando aquele objeto. As fotos usadas em cada teste tinham sua ordem alterada, de modo à sempre mudar a primeira imagem vista a cada novo teste. Dessa forma, a percepção dos participantes seria diferente mesmo vendo o mesmo conjunto de cinco imagens. Esta etapa tinha como objetivo analisar se e como o participante percebia qual era o objeto em questão e como manuseá-lo, mesmo isolado de seu contexto e sem nenhuma informação prévia, baseando-se somente nos affordances oferecidos pelo próprio objeto.

Se o participante não identificasse o produto presente na imagem ele era direcionado à foto seguinte, outra maçaneta na sequência de cinco, a qual teria que procurar identificar novamente. Caso identificasse corretamente qual era o objeto na imagem, ele era levado, então, a classificar a maçaneta em questão de acordo com uma série de sete pares de características presentes na escala de diferencial semântico, como mostrado anteriormente na figura 21 . Nessa etapa, além de saber como o participante percebia o objeto mostrado, também era do interesse desta pesquisa entender como se dava essa percepção e quais as impressões do participante acerca da imagem mostrada, de forma que, para cada característica atribuída à maçaneta, foi pedido que o participante explicasse sua classificação.

Também foi pedido, a seguir, que cada um enumerasse alguns modelos de carros, mostrados anteriormente na figura 22 , em que pensava que
Realização:
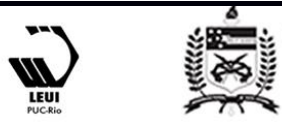


\section{$16^{\circ}$ \\ ERGODESIGN USIHC CINAHPA}

poderia encontrar a maçaneta em questão, relacionando o seu formato ao seu possível contexto, guiado por desenhos auxiliares e seus respectivos nomes. Era possível escolher mais de um modelo de carro, mas também foi pedido que o participante justificasse suas escolhas. Esses procedimentos eram repetidos para cada maçaneta identificada corretamente. Ao final, foi realizado um pequeno questionário no qual se procurava saber um pouco mais sobre o cotidiano de uso do participante com relação ao veículo, se possuía habilitação para motorista e qual a frequência que andava de carro, por exemplo. Dessa maneira, coletavam-se mais dados sobre cada participante, $o$ que pode auxiliar na análise dos dados ajudando a relacionar a percepção ou não das maçanetas com a periodicidade que os usuários utilizam o veículo.

\subsection{Perfil dos participantes}

Para a participação nos testes não houve nenhum tipo de impedimento para caracterizar os participantes. Não era necessário possuir habilitação para motorista ou ter mais de 18 anos e, apesar de dificultar a calibragem do aparelho Eyetracking, os participantes que usavam óculos também não foram excluídos do teste.

A participação era voluntária e os participantes foram escolhidos minutos antes da realização do teste, de acordo com a disponibilidade do mesmo, por meio de abordagens aleatórias. Apesar de não ter sido procurado nenhum perfil específico de participante, notou-se uma grande participação de alunos da graduação da PUC-Rio, estudantes do curso de design, com idades entre 20 e 25 anos (70\%). Os demais (30\%) eram estudantes de outros cursos de graduação ou da pós-graduação da mesma universidade.

\section{Análise dos resultados}

Depois de terminada a fase de testes, começou-se a fazer uma série de análises com o material obtido. A princípio foram realizadas análises prévias com base nos primeiros achados dos testes, sem um aprofundamento maior no que foi obtido usando o Eyetracking. Percebeu-se que muitos participantes, quando tinham que identificar o objeto mostrado $16^{\circ}$ Ergodesign - Congresso Internacional de Ergonomia e Usabilidade de Interfaces Humano Tecnológica: Produto, Informações Ambientes Construídos e Transporte

$16^{\circ}$ USIHC - Congresso Internacional de Ergonomia e Usabilidade de Interfaces Humano Computador

CINAHPA | 2017 - Congresso Internacional de Ambientes Hipermídia para Aprendizagem.

na foto, olhavam para as extremidades das maçanetas e mantinham seus olhos se movimentando de um lado para o outro até falarem suas respostas. Também foi possível notar que outros participantes, além de olharem para as extremidades, olhavam para o centro da maçaneta também, fazendo um movimento ocular semelhante a um "triângulo".

Nas maçanetas mais arredondadas foi possível notar que os olhos dos participantes acompanharam a curva presente no objeto, enquanto que em maçanetas mais retilíneas o mesmo não se notou. Nessa etapa de análises prévias também se observou que a parte côncava das maçanetas auxiliou bastante os participantes a identificar o objeto, já que tal área criava uma sombra na imagem, ajudando-os a entender como o manuseio se daria.

No decorrer dos testes, também foi percebido que algumas respostas eram comuns a diferentes participantes. Maçanetas com formatos mais curvos e com extremidades mais arredondadas eram mais rápido e facilmente reconhecidas como sendo maçanetas do que aquelas que apresentavam formas mais alongadas e com desenhos mais retilíneos. Acredita-se que esse resultado se deve, principalmente, devido àqueles serem os modelos mais comuns em carros populares brasileiros. Da mesma maneira, as maçanetas que possuíam formatos muito diferentes do encontrado no cotidiano dos participantes demandavam mais tempo de reconhecimento ou não eram identificadas, frequentemente confundidas com outros objetos. Quando isso acontecia, percebia-se que o participante, mesmo não identificando corretamente o objeto em si, era capaz de identificar o mecanismo operante por meio de associações com algum outro objeto do cotidiano com um formato semelhante, como aberturas de $\mathrm{CD} / \mathrm{DVD}$ em computadores e rádios, por exemplo. Nesses casos, essa associação era feita porque a maçaneta em questão (figura 14 apresentada anteriormente) apresentava um botão que destravava a alavanca que abria a porta, peça que foi confundida com o compartimento que se abre para acomodar o CD em aparelhos eletrônicos. Alguns participantes também associaram algumas
Realização:

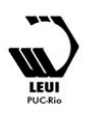




\section{$16^{\circ}$ \\ ERGODESIGN USIHC CINAHPA}

maçanetas a outras partes do carro, como os faróis (figura 18 mostrada anteriormente) ou a abertura para o tanque de abastecimento de combustível (figura 08 e 12 apresentadas anteriormente), devido principalmente ao formato das maçanetas em questão lembrarem essas peças em automóveis. Algumas maçanetas foram confundidas, ainda, com partes de eletrodomésticos (figuras 06 e 10), como puxadores de porta de geladeira ou alças de ferro de passar roupa.

\subsection{Atributos percebidos nas maçanetas}

Com base nas análises prévias dos resultados obtidos no diferencial semântico a partir do uso do aparelho Eyetracking, pode-se concluir que maçanetas mais arredondadas passam a impressão de serem mais "retrôs", ao passo que aquelas mais alongadas são consideradas mais futuristas. Ao mesmo tempo, aquelas consideradas mais frágeis e propensas a pequenos defeitos com o uso são, de acordo com a maioria dos participantes nos testes, mais retilíneas. Notou-se também que houve participantes que consideraram determinadas maçanetas, como nas figuras 02 e 06 , como frágeis, contrapondo o que pensavam os pesquisadores a respeito do mesmo objeto.

Acreditava-se que, por conta do mecanismo de manuseio, ou seja, do modo como e onde o usuário deve segurar a maçaneta para abrir a porta, determinadas maçanetas ofereciam mais segurança ao usuário do que outras, mas não foi isso que pôde ser percebido no decorrer dos testes. Pensavase que, por exemplo, as maçanetas nas quais o usuário teria que agarrar e puxar para abrir a porta ofereciam mais segurança para executar este movimento do que outras em que os dedos do usuário se posicionam por baixo da maçaneta apenas para puxar. Porém, o que foi percebido foi que este mesmo pensamento não era comum a todos os participantes, já que muitos consideraram essas maçanetas frágeis por serem mais finas que as demais. Exemplares que possuíam botões que deveriam ser apertados a fim de destravar a maçaneta em questão também foram considerados mais frágeis porque o risco de o botão apresentar problemas de funcionamento no decorrer dos usos do carro poderia ser grande. Leitor de impressão digital instalado em uma das maçanetas usadas nos testes também foi apontado como uma possível fragilidade do objeto, uma vez que poderia apresentar problemas de funcionamento e dificultar, ou até mesmo impedir, o acesso ao carro.

A relação entre as maçanetas mostradas e os modelos dos carros vistos também foi interessante analisar. Aquelas maçanetas com desenhos mais arrojados e incomuns, e muitas vezes mais difíceis de serem identificadas, eram associadas a carros esportivos, modelos que se propõe a inovar mais nos produtos. Da mesma maneira, as que apresentavam desenhos mais alongados e retilíneos eram associadas a carros sedan por conta do padrão mais clássico e com menos detalhes, assim como maçanetas encontradas nesses modelos de carro. Maçanetas com desenhos mais curvos eram associadas, principalmente, a carros hatch, relacionadas a esse modelo em diversos depoimentos dos participantes a uma aparência mais jovem e moderna.

Com essas análises prévias pôde-se perceber que muito do que havia sido pensado sobre os comportamentos dos participantes não foi seguido e, ao mesmo tempo, algumas observações feitas pelos mesmos não tinham sido feitas pelos pesquisadores antes do início dos testes. Isso foi interessante para abranger as considerações sobre o que é percebido ou não nas maçanetas de carros pelos usuários das mesmas e quais os affordances presentes ali que podem ser mais chamativos que os demais.

\subsection{Percepção de Usabilidade (Painéis Semânticos)}

Sendo assim, percebeu-se a necessidade de detalhar as análises de uma maneira qualitativa. Portanto, aproveitar as falas do que foi gravado durante os testes de cada participante, foi importante para obter dados mais pessoais num teste padrão, ou seja, conforme os participantes falavam, eles expressavam opiniões mais particulares, que acabavam explicitando melhor o que vinha sendo feito com a escala de diferencial semântico junto dos segmentos de carros (representados por desenhos). Os áudios foram
Realização:

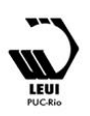




\section{$16^{\circ}$ \\ ERGODESIGN USIHC CINAHPA}

gravados em formato de vídeo para que fossem acompanhados das imagens que os participantes viram e do movimento que eles fizeram com os olhos (captado pelo Eyetracking). Este conjunto permitiu que painéis semânticos (figura 27) fossem criados para qualificar as nove maçanetas (dentre as dez maçanetas, uma não foi identificada por nenhum participante) identificadas nos testes. Para esses painéis, foi escolhida uma diretriz, que se repetiu em cada painel, acompanhada de seis variáveis. Escolheu-se como diretriz a classificação "fácil/difícil de usar", visto que o intuito da análise era a de obter as percepções de usabilidade a partir das variáveis de cada painel, entre essas: retrô/futurista; simples/complexo; discreto/chamativo; antiquado/atual; robusto/frágil; confortável/desconfortável.

E assim, foram inseridas falas importantes de cada participante, que classificavam e qualificavam de uma maneira bastante pessoal suas impressões sobre as maçanetas. Em forma de gráfico, as imagens das nove maçanetas foram posicionadas de acordo com a combinação das variáveis e acompanharam as falas que justificam a tal combinação. Cada painel ajuda a entender, de uma maneira mais aprofundada, os dados quantitativos que foram obtidos previamente com a escala da figura 21.

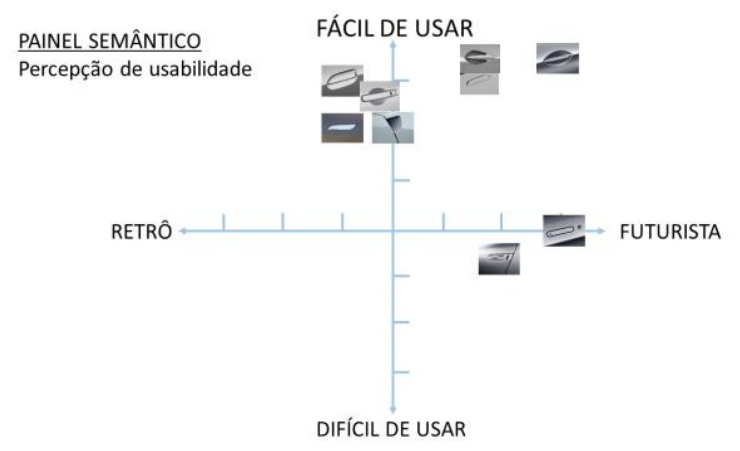

Figura 27. Exemplo de um dos painéis semânticos para o entendimento da usabilidade das maçanetas

Na variável retrô/futurista, as maçanetas classificadas como retrô foram caracterizadas como mais fáceis de usar e ganharam atributos como: "não tem tanta informação" e "arredondada" (figura 20). Esses atributos também estavam $16^{\circ}$ Ergodesign - Congresso Internacional de Ergonomia e Usabilidade de Interfaces Humano Tecnológica: Produto, Informações Ambientes Construídos e Transporte

$16^{\circ}$ USIHC - Congresso Internacional de Ergonomia e Usabilidade de Interfaces Humano Computador

CINAHPA | 2017 - Congresso Internacional de Ambientes Hipermídia para Aprendizagem.

relacionados às memórias dos participantes, ou seja, um passado imagético para determinar tais maçanetas como retrô. Já as maçanetas futuristas, dividiram-se em neutras no fácil/difícil de usar e muito fáceis de usar. As muito fáceis foram consideradas aerodinâmicas, com linhas secas e pontudas, dando sensação de movimento (figura 02).

Na variável simples/complexo, mesmo as maçanetas mais complexas não foram classificadas como difíceis de usar. Essa variável, segundo a fala dos participantes, foi analisada com características pertinentes à funcionalidade/forma da maçaneta: "muito simples, porque é só colocar a mão e puxar" (figura 10).

Na variável discreto/chamativo, a maioria foi classificada no grupo das "discretas", que ganharam atributos como: "sem relevo" (figura 12), "menos linhas", "não chama a atenção" (figura 06) e "camuflada" (mesma cor do carro). Uma característica para a maçaneta chamativa foi a de ser "brilhante" (figura 18). A relação de serem discretas com o fato de serem fáceis de usar percebeu-se nas seguintes falas: "menos linhas" e "design simples".

Na variável antiquado/atual, somente uma maçaneta ficou como antiquada (a mesma foi tida como retrô no outro painel anterior). Ela recebeu tal classificação com a seguinte fala: "os carros de hoje em dia já têm uma maçaneta mais diferente" (figura 20).

Na variável robusto/frágil, a maioria ficou neutra. A maçaneta que foi tida como a mais frágil "é fina" (figura 04), outra "poderia emperrar" (figura 12). Já as robustas variaram como: "aparência que passa segurança" (figura 08), "retangular, não tem cara de frágil" (figura 06) e "forma agressiva" (figura 10).

Na variável confortável/desconfortável, a maçaneta mais desconfortável demanda "força com as pontas dos dedos" (figura 20), já uma maçaneta confortável tem "bastante espaço para colocar a mão e não esmagaria os dedos" (figura 02). 
$16^{\circ}$ Ergodesign - Congresso Internacional de Ergonomia e Usabilidade de Interfaces Humano Tecnológica: Produto, Informações Ambientes Construídos e Transporte

$16^{\circ}$ USIHC - Congresso Internacional de Ergonomia e Usabilidade de Interfaces Humano Computador

CINAHPA | 2017 - Congresso Internacional de Ambientes Hipermídia para Aprendizagem.

\section{Conclusão}

Em conclusão, pode-se dizer que, apesar de alguns participantes terem encontrado dificuldades no entendimento das imagens, os affordances foram entendidos corretamente em sua maioria. De acordo com a forma, como já era esperado, algumas maçanetas eram mais rapidamente entendidas do que outras, o que reflete um affordance mais bem aplicado ao produto em questão. Por conta da falta de informação externa e do contexto em que aquele objeto pudesse estar inserido notou-se que os participantes demoraram mais tempo para entender o objeto do que se o estivessem vendo materializado.

Como já foi mencionado anteriormente, Gibson (1979) afirma que a compreensão de como o objeto deve ser manuseado deve estar clara mesmo estando ele fora do seu contexto de uso, ou seja, sem ajudas externas. Levando em consideração a percepção de Gibson, pode-se afirmar que algumas das maçanetas testadas não são compreendidas com eficácia fora do seu contexto de uso, como por exemplo, as apresentadas nas figuras 04,16 e 18 anteriormente.

Acredita-se que esta pesquisa pode contribuir e auxiliar no desenvolvimento de futuras maçanetas em veículos, tornando possível a criação de produtos mais facilmente entendidos e manipulados pelos usuários, independentemente do contexto em que estejam inseridos.

\section{BIBLIOGRAFIA}

GIBSON, J. J. The Ecological Approach to Visual Perception. Houghton Mifflin, 1979. 322p.

NORMAN, D. Affordance, Conventions and Design. Interactions, v.6, p.38-43, 1999.

HSU, S. H. et al. A semantic differential study of designers' and users' product form perception.

International Journal of Industrial Ergonomics, v 25, p. 375- 391, 2000.

\section{Agradecimentos}

À FAPERJ e ao CNPq com o auxílio e incentivo com bolsas de pesquisa.

À Elisa Kronemberger, aluna de graduação em Design da PUC-Rio, pelo trabalho voluntário no início da pesquisa. 